\title{
Spreading depolarization in acute brain injury inhibited by ketamine: a prospective, randomized, multiple crossover trial
}

\author{
Andrew P. Carlson, MD, MS-CR, ${ }^{1}$ Mohammad Abbas, MD,, Robert L. Alunday, MD, ${ }^{1}$ \\ Fares Qeadan, $\mathrm{PhD},{ }^{2}$ and C. William Shuttleworth, $\mathrm{PhD}^{3}$ \\ Departments of ${ }^{1}$ Neurosurgery, ${ }^{2}$ Internal Medicine, and ${ }^{3}$ Neurosciences, University of New Mexico School of Medicine, \\ Albuquerque, New Mexico
}

\begin{abstract}
OBJECTIVE Retrospective clinical data and case studies support a therapeutic effect of ketamine in suppression of spreading depolarization (SD) following brain injury. Preclinical data strongly support efficacy in terms of frequency of SD as well as recovery from electrocorticography $(E C O G)$ depression. The authors present the results of the first prospective controlled clinical trial testing the role of ketamine used for clinical sedation on occurrence of SD.

METHODS Ten patients with severe traumatic brain injury (TBI) or aneurysmal subarachnoid hemorrhage (SAH) were recruited for this pilot trial. A standard ECoG strip was placed at the time of craniotomy, and the patients were then placed on an alternating every-6-hour schedule of ketamine or other sedation agent. The order of treatment was randomized. The ketamine dose was adjusted to clinical effect or maintained at a subanesthetic basal dose $(0.1 \mathrm{mg} / \mathrm{kg} / \mathrm{hr})$ if no sedation was required. SD was scored using standard criteria, blinded to ketamine dosing. Occurrence of SD was compared with the hourly dose of ketamine to determine the effect of ketamine on SD occurrence.

RESULTS Successful ECOG recordings were obtained in all 10 patients: 8 with SAH and 2 with TBI. There were a total of 1642 hours of observations with adequate ECoG: 833 hours off ketamine and 809 hours on ketamine. Analysis revealed a strong dose-dependent effect such that hours off ketamine or on doses of less than $1.15 \mathrm{mg} / \mathrm{kg} / \mathrm{hr}$ were associated with an increased risk of SD compared with hours on doses of $1.15 \mathrm{mg} / \mathrm{kg} / \mathrm{hr}$ or more $(\mathrm{OR} 13.838,95 \% \mathrm{Cl}$ $1.99-1000)$. This odds ratio decreased with lower doses of $1.0 \mathrm{mg} / \mathrm{kg} / \mathrm{hr}$ (OR 4.924, 95\% Cl 1.337-43.516), $0.85 \mathrm{mg} / \mathrm{kg} /$ $\mathrm{hr}(\mathrm{OR} 3.323,95 \% \mathrm{Cl} 1.139-16.074)$, and $0.70 \mathrm{mg} / \mathrm{kg} / \mathrm{hr}$ (OR 2.725, 95\% Cl 1.068-9.898) to a threshold of no effect at $0.55 \mathrm{mg} / \mathrm{kg} / \mathrm{hr}$ (OR 1.043, 95\% Cl 0.565-2.135). When all ketamine data were pooled (i.e., on ketamine at any dose vs off ketamine), a nonsignificant overall trend toward less SD during hours on ketamine $\left(\chi^{2}=3.86, p=0.42\right)$ was observed. CONCLUSIONS Ketamine effectively inhibits SD over a wide range of doses commonly used for sedation, even in nonintubated patients. These data also provide the first prospective evidence that the occurrence of SD can be influenced by clinical intervention and does not simply represent an unavoidable epiphenomenon after injury. These data provide the basis for future studies assessing clinical improvement with SD-directed therapy.

Clinical trial registration no.: NCT02501941 (clinicaltrials.gov)

https://thejns.org/doi/abs/10.3171/2017.12.JNS171665
\end{abstract}

KEYWORDS subarachnoid hemorrhage; vasospasm; spreading depression; spreading depolarization; delayed cerebral ischemia; vascular disorders; traumatic brain injury

$\mathrm{R}$ ECENT work has confirmed that large, propagating waves of mass neuronal and glial depolarization (spreading depolarization [SD]) are important contributors to the progression of brain injuries in humans..$^{10,19}$ SD can be initiated by focal tissue ischemia, trauma, or excessive neuronal activation in a brain region that has pathologically limited vascular perfusion. ${ }^{25,34,37}$ Propagation is slow $(2-6 \mathrm{~mm} / \mathrm{min})$, as it is caused by regenerative extracellular accumulation of extracellular glutamate and/ or $\mathrm{K}+.^{2}$ Injury expansion is a consequence of the extreme

ABBREVIATIONS DC = direct current; ECOG = electrocorticography; ICP = intracranial pressure; $\mathrm{SAH}=$ subarachnoid hemorrhage; SD = spreading depolarization; TBI = traumatic brain injury.

SUBMITTED July 7, 2017. ACCEPTED December 14, 2017.

INCLUDE WHEN CITING Published online May 25, 2018; DOI: 10.3171/2017.12.JNS171665. 
ionic disruptions and metabolic demand placed on brain tissue by SD events, each of which last for minutes. While normally perfused brain can recover from SD without injury, brain with marginal perfusion may not be able to recover from repeat $\mathrm{SD}$, leading to infarct expansion. Impaired neurovascular coupling in the wake of SD likely exacerbates deleterious consequences of an injured brain. ${ }^{9}$ Consistent with predictions from preclinical models, clusters of SDs are linked to infarct progression in brain injury in humans. ${ }^{12,27}$

SD has been found to occur in most $(60 \%-80 \%)$ patients in the days following severe traumatic brain injury (TBI) and subarachnoid hemorrhage $(\mathrm{SAH})^{12,17}$ and has been correlated with worse clinical outcomes. ${ }^{17}$ Clinical efforts to limit SD are still in the early stages of exploration. There are many unanswered questions regarding the optimal agent to target SD and how to ensure that therapeutics are delivered to the at-risk tissue despite potentially lower blood flow to injured brain. Initial case report data have suggested that in patients with very frequent SD, ketamine exerted a profound and complete suppressive effect on SD. ${ }^{31,33}$ This led to the retrospective review of electrocorticography $(\mathrm{ECoG})$ recordings in 115 patients across participating centers, which demonstrated that ketamine, unlike other agents, had a consistent, dose-dependent, suppressive effect on the incidence of SD. ${ }^{23}$ Based on these data, we designed a pilot trial to prospectively test the efficacy of ketamine sedation in the neuro-ICU in terms of SD suppression (clinical trial registration no. NCT02501941 [clinicaltrials.gov]).

\section{Methods}

\section{Neuromonitoring and ECoG}

We prospectively included 10 patients with aneurysmal SAH or severe TBI with injury severity requiring invasive monitoring and craniotomy (for aneurysm clipping in SAH or hemicraniectomy in TBI). Consent was obtained via a legally authorized representative prior to surgery, and the study was approved by the University of New Mexico Human Research Protections Office. Monitoring of ECoG for SD was conducted using established techniques..$^{10,18}$ Briefly, at the time of surgery, a $1 \times 6$ platinum cortical electrode (Integra Epilepsy) was placed on either the frontal or temporal lobe and tunneled subcutaneously through a posterior burr hole. The location of the strip was intended to be in potentially at-risk territory without being in completed infarction. At-risk territory was defined in SAH as the lobe most likely to experience vasospasm (e.g., temporal lobe for the middle cerebral artery, medial frontal lobe for the anterior communicating artery). In TBI, the strip was placed adjacent to any visibly contused brain. Monitoring was conducted using a full-spectrum direct current (DC) amplifier and collected using a Moberg Component Neuromonitoring system (CNS; Moberg Research Inc.). Real-time data were reviewed using the Moberg Reader desktop program for ongoing data integrity. The strip was removed at the bedside when clinical invasive monitoring was discontinued (typically 7-14 days). After collection, data were exported to LabChart (version 8.0, ADInstruments) where raw DC data for each channel as well as high-frequency filtered $(0.5-50 \mathrm{~Hz})$ data were displayed, together with the 60-second integral of the power of the filtered data, per standard analysis recommendations. ${ }^{10}$

\section{Ketamine Dosing}

After the patient returned from the operating room, a washout period was maintained to avoid immediate postoperative anesthesia effects. This period ranged from 1 to 5 hours to begin medication dosing on a standardized schedule (see below). The patients were then randomized to start on either ketamine sedation or the other sedation regimen. The other sedation agent was determined per the intensivist. This agent was typically propofol or dexmedetomidine in intubated patients and midazolam or dexmedetomidine in nonintubated patients. Sedation was then titrated to a Riker Sedation-Agitation Scale score of 4 (calm, easily arousable, follows commands). ${ }^{29} \mathrm{~A}$ standardized hospital-wide ketamine titration protocol was adopted and approved for use to ensure consistency of sedation. The randomized start order was then initiated at the next hour divisible by 6 (06:00, 12:00, 18:00, or 24:00). Medications were then alternated every 6 hours. If no sedation was required, a basal rate of $0.1 \mathrm{mg} / \mathrm{kg} / \mathrm{hr}$ of ketamine was then continued during the ketamine-assigned hours, and no medications were given during the "other" hours. This regimen was continued until the monitoring electrode was removed. After electrode removal, there were no further study-related interventions, and routine clinical care continued.

\section{Analysis}

SD was identified using standard, previously validated techniques. ${ }^{18}$ Briefly, this involved identification of a characteristic of DC deflection typically accompanied by suppression of high-frequency ECoG data occurring on adjacent electrodes with temporal separation of $<10$ minutes. Other nuances to scoring have been previously discussed, ${ }^{10}$ and cases of uncertainty were resolved by consensus between the senior authors (A.P.C. and C.W.S.) or not scored as SD. SD was scored independently and blinded to the medication regimen described below. Periods of poor data or lead disconnection were marked for exclusion in analysis. The duration of depression and of DC deflection were then scored for each SD. The number of SD occurrences per hour was then noted for each hour of recording. After blinded scoring, the total hourly dose of ketamine for each hour of ECoG recording was then extracted. Due to the multiple crossover design, patients acted as their own control, for both injury type and time after injury, and time of day. For this reason, overall hours were compared independently of patients. We primarily chose this pooled method for this pilot analysis because effects on SD, such as injury type, severity, presence of vasospasm or stroke, systemic hypotension, and other factors, could severely skew a per-patient analysis, even if internally controlled. The chi-square test ${ }^{1}$ was used to determine the statistical significance of odds for the occurrence of SD on versus off ketamine.

Due to the known dose-dependent effects of ketamine, ${ }^{32}$ a preplanned dose-response analysis was also then per- 
TABLE 1. Participant characteristics

\begin{tabular}{|c|c|c|c|}
\hline & Value & $95 \% \mathrm{Cl}$ & p Value* \\
\hline Sex & & & 0.2059 \\
\hline Male & $3(30 \%)$ & $(0.00-64.56)$ & \\
\hline Female & $7(70 \%)$ & $(35.45-100.00)$ & \\
\hline Diagnosis & & & 0.0578 \\
\hline TBI & $2(20 \%)$ & $(0.00-50.16)$ & \\
\hline Aneurysmal SAH & $8(80 \%)$ & $(49.84-100.00)$ & \\
\hline History of migraine & & & 0.0450 \\
\hline Yes & $2(20 \%)$ & $(0.00-50.16)$ & \\
\hline No & $7(70 \%)$ & $(35.45-100.00)$ & \\
\hline Unknown & $1(10 \%)$ & $(0.00-32.62)$ & \\
\hline Race/ethnicity & & & 0.2059 \\
\hline White/Hispanic & $7(70 \%)$ & $(35.45-100.00)$ & \\
\hline White/non-Hispanic & $3(30 \%)$ & $(0.00-64.56)$ & \\
\hline Mean age in yrs & $60.80(16.01)$ & $(49.35-72.25)$ & \\
\hline Mean weight in kg & $84.14(19.16)$ & $(70.43-97.85)$ & \\
\hline
\end{tabular}

Values are presented as the number of patients unless stated otherwise. Mean values are presented with standard deviations in parentheses.

* Chi-square test.

formed to determine a threshold of dosing for ketamine suppression. The Cochran-Armitage ${ }^{3,6}$ trend test was used to test the trend in SD proportions in ketamine dose groups. Logistic regression modeling ${ }^{1}$ was used to estimate the dose effect associated with sequential dose reductions in ketamine. Appropriate intervals were determined by manual calculations of various dosing intervals and validation of a significant trend using the aforementioned technique. In addition, the duration of depression was also compared between hours on and off of ketamine to determine if there was an effect of shortening this depression. Duration of depression was defined as the longest recoverable depression after each SD. The initiation of the loss of the integral of the power was used as the start of depression and the beginning of recovery as the end of depression, as previously reported..$^{10}$ Finally, to address the historical concern of possible increased intracranial pressure (ICP) with ketamine, ${ }^{7}$ the correlation of ketamine dose with hourly recorded ICP was studied using mixed-effects modeling with patients as a random variable. Individual patient regression analyses were also performed to determine if there was a significant effect in some patients. Analysis was performed using SAS (version 9.4, SAS Institute Inc.).

\section{Results \\ Recordings}

Successful ECoG recordings were obtained in all 10 patients. Table 1 shows demographic characteristics of the patients. Figure 1 shows an example SD and electrode strip position. Eight patients had aneurysmal SAH requiring clipping, and 2 had severe TBI with elevated ICP that was unresponsive to medical management and required hemicraniectomy. No patient had a serious adverse event related to the monitoring or medication alternation. One patient experienced agitation during ketamine dosing after 3 days, and so the medication alternation was discontinued and the electrode strip removed. In this patient, there was persistent severe agitation requiring multiple sedation regimens; the agitation was not thought to be directly related to ketamine administration. There were no instances of wound leakage, hematoma, or other complications noted around the electrode.

\section{Moderate-Dose Ketamine Inhibits SD}

There were a total of 1642 hours of observations with adequate ECoG: 833 hours off ketamine and 809 hours on ketamine. The analysis revealed a strong dose-dependent effect such that hours off ketamine or on doses of less than $1.15 \mathrm{mg} / \mathrm{kg} / \mathrm{hr}$ were associated with an increased risk of SD compared with hours on doses of $1.15 \mathrm{mg} / \mathrm{kg} / \mathrm{hr}$ or

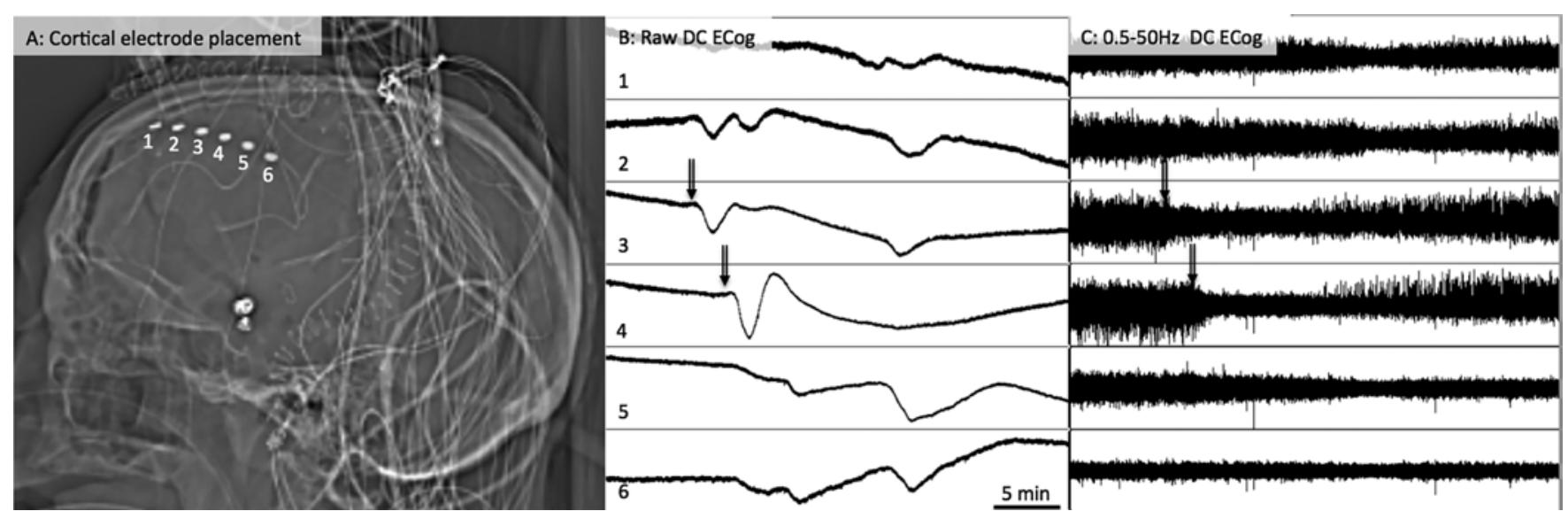

FIG. 1. Example patient and SD. A: Lateral scout CT scan demonstrating the location of the electrode strip on the cortical surface. Each lead is labeled 1-6. B: Full-spectrum, referential DC recordings from the electrode strip. The data are condensed to the scale shown at the bottom. The double arrows show 2 definite DC shifts of SD in electrodes 3 and 4 . There are more irregular DC shifts on the other channels, which also likely represent continuation of the SD wave. C: Filtered data on the same 6 electrodes over the same time interval as in $\mathrm{B}$. Note that the start of the depression of the high-frequency data (double arrows) occurs simultaneously with the DC shift, defining the SD. 


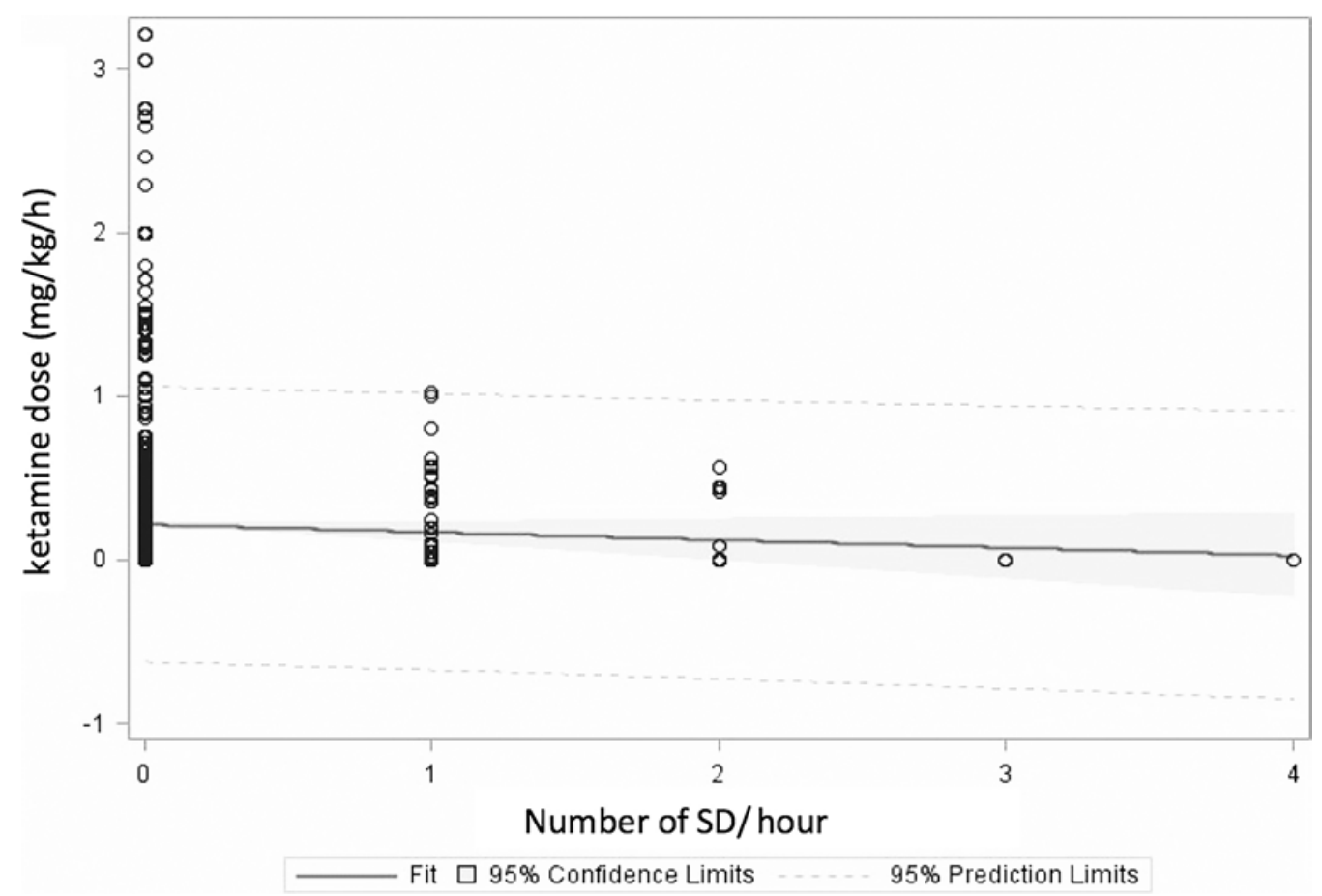

FIG. 2. Plot of frequency of SD occurrences per hour (circles) versus dose of ketamine. All SD occurrences were at doses below $1.15 \mathrm{mg} / \mathrm{kg} / \mathrm{hr}$. A further trend toward less frequent occurrence (SD/hr) can also be clearly noted, though the numbers with $>2 \mathrm{SD} /$ hr are small.

more (OR 13.838, 95\% CI 1.99-1000; Fig. 2). We then tested reductions of both $0.1 \mathrm{mg} / \mathrm{kg} / \mathrm{hr}$ and $0.15 \mathrm{mg} / \mathrm{kg} / \mathrm{hr}$. While both displayed a significant dose-dependent reduction in effect with sequential dose decreases, the interval of $1.15 \mathrm{mg} / \mathrm{kg} / \mathrm{hr}$ resulted in a consistent and highly significant trend using the Cochran-Armitage test and was chosen for further analysis $(Z=-3.021, \operatorname{dim}=5, p=0.00126)$. The odds of occurrence of SD progressively decreased as each $0.15-\mathrm{mg} / \mathrm{kg} / \mathrm{hr}$ interval was tested at doses of $1.0 \mathrm{mg} /$ $\mathrm{kg} / \mathrm{hr}$ (OR 4.924, 95\% CI 1.337-43.516), $0.85 \mathrm{mg} / \mathrm{kg} / \mathrm{hr}$ (OR 3.323, 95\% CI 1.139-16.074), and $0.70 \mathrm{mg} / \mathrm{kg} / \mathrm{hr}$ (OR $2.725,95 \%$ CI $1.068-9.898)$ to a threshold of no effect at $0.55 \mathrm{mg} / \mathrm{kg} / \mathrm{hr}$ (OR $1.043,95 \%$ CI 0.565-2.135). In linear regression, a decrease of $0.15 \mathrm{mg} / \mathrm{kg} / \mathrm{hr}$ in dose was found to be associated with a twofold increase in the odds of SD (OR 1.973, 95\% CI 1.265-3.503). We repeated this dose effect analysis per patient and found that while the individual dose effects were not significant, there was a trend toward reduction of SD with an increased dose of ketamine in 7 of 9 patients with SD. This supports the use of the pooled analysis as a reasonable summary of the overall effect of ketamine on SD across patients. When all ketamine data were pooled (i.e., on ketamine at any dose vs off ketamine), a nonsignificant overall trend toward less SD during hours on ketamine $\left(\chi^{2}=3.86, p=0.42\right)$ was observed.

\section{Effect of Ketamine on ECoG Suppression and DC Deflection}

There was nonsignificant effect of ketamine on the mean duration of depression after SD $(\mathrm{F}=2.62, \mathrm{p}=0.11)$. We also tested the effect of higher-dose ketamine (below the threshold for complete suppression of SD), but did not detect a significant effect on duration of these events either. The number of events was relatively small, and our study was not powered to detect such an effect, which, to date, has not been described in humans despite significant data in animals.

\section{Effect of Ketamine on ICP}

In our mixed-effects model of the effect of ketamine on ICP, we found no significant overall effect $(p=0.6052)$. In individual patient regression analysis, only 2 patients were found to have a positive association of ketamine with ICP (not significant), while most were neutral; 3 patients seemed to show a protective effect of higher doses of ketamine on ICP, one of which was significant (Fig. 3).

\section{Discussion}

This study provides the first prospective evidence supporting the efficacy of ketamine in decreasing the SD incidence in ICU patients with acute neurological injury. Significant benefit was seen at doses greater than $1.15 \mathrm{mg} /$ $\mathrm{kg} / \mathrm{hr}$ with a very large effect size of over 13 times the odds of SD at lower doses. The effect of all doses of ketamine on SD incidence was not significant, likely due to the influence on the group analysis from the patients on very low doses $(0.1 \mathrm{mg} / \mathrm{kg} / \mathrm{hr})$ when no clinical sedation was required. The pragmatic experimental approach used here was necessary in a pilot trial, where the use of the medications was titrated for sedation purposes only. The dose dependency of the effect, with a progressive increase in the odds ratio over the range of $0.55 \mathrm{mg} / \mathrm{kg} / \mathrm{hr}$ to 1.15 


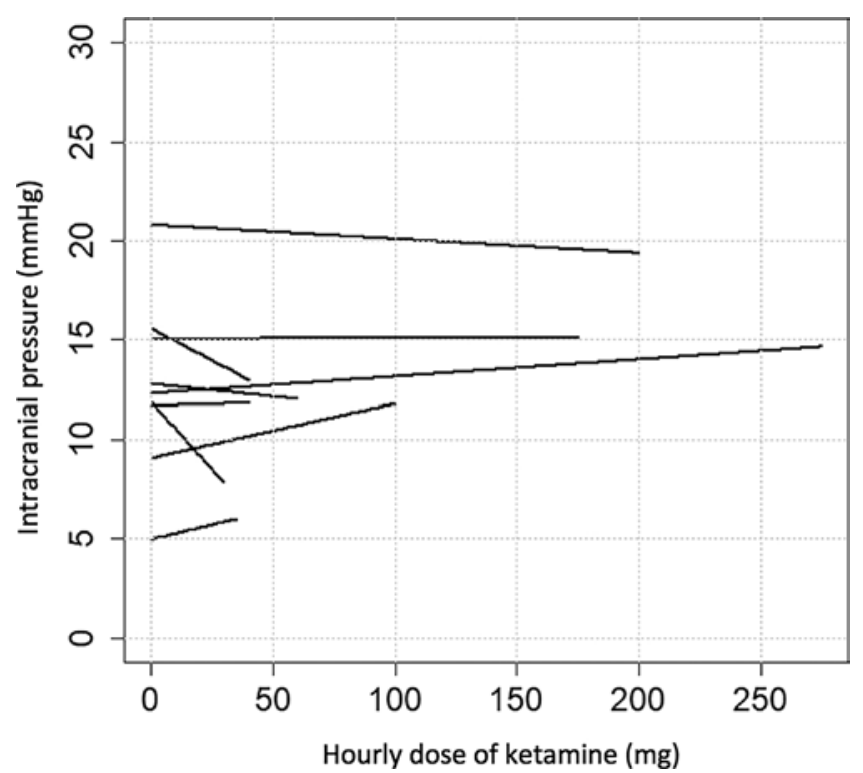

FIG. 3. Individual linear regression analysis of each of the 9 patients with ICP monitoring regarding the effect of ketamine on ICP. The overall mixed-effects model showed no significant association. Note that in individual patients, the trends are quite variable, with some patients showing a negative association.

$\mathrm{mg} / \mathrm{kg} / \mathrm{hr}$, adds to the strength of the conclusion of clinical efficacy on SD. These pilot data also provide proof-ofconcept confirmation that clinical trials targeting SD are technically feasible. Given the strong association of SD with clinical outcome, ${ }^{10,12,19,20}$ we believe that such trials targeting SD and the well-documented associated deleterious effects would be highly likely to result in improved clinical outcomes.

The concern that SD may be either an epiphenomenon of brain injury or merely a non-causative marker of injury severity is clearly an important issue for the development of interventions. However, multiple lines of preclinical and clinical evidence over the past several years support a causative role of SD in injury progression after brain injury. One line of evidence is based on animal and brain slice models, where SD clearly leads to progressive tissue injury in vulnerable tissues. ${ }^{2,5,19,37}$ Clinical data also strongly support the independent deleterious effect of SD beyond being a marker for severity of injury. Hartings et al. ${ }^{17}$ examined 109 patients with severe TBI across multiple centers and concluded that occurrence of SD-particularly that occurring in already dysfunctional brain-corresponded to a greater than 7 times odds of poor outcome. Dreier et al..$^{12}$ demonstrated the temporally relevant nature of these events in SAH patients, where clusters of SD were reliably observed preceding every documented episode of delayed ischemic neurological deficit. This observation argues strongly that the clusters play a causative role in such clinical deterioration. In a study correlating brain microdialysis with occurrence of SD, Feuerstein et al. noted sequential and stepwise reduction in glucose with each SD..$^{15}$ Remarkably, they also noted that if there was a period of no SD, glucose would increase and again be depleted with sequential SD when the events recurred. Dreier et al. ${ }^{11}$ and Hinzman et al. ${ }^{24}$ have similarly convincingly demonstrated repeated waves of cortical ischemia accompanying $\mathrm{SD}$, particularly in injured brain, leading to expansion of infarcts.

There are, unquestionably, multiple issues that remain to be addressed regarding how best to target SD as a potential mechanism to improve outcomes after acute neurological injury. These issues include the optimal patients, agent, delivery, and timing. We chose to begin the current pilot trial in this manner because SAH and TBI patients are known to have a high frequency of SD but do not all go on to experience expansion of infarction.

We chose to study ketamine because there are clear preclinical data regarding the effect of ketamine on both occurrence and severity of $\mathrm{SD},{ }^{16,22}$ because there are preliminary reports of efficacy for SD, 23,30,31 and because it is widely clinically available and used for sedation in critical care. Ketamine, a noncompetitive $N$-methyl-D-aspartate receptor antagonist, is thought to block SD by binding and stabilizing the glutamate binding site, which in turn stabilizes the membrane from the mass depolarization of SD. ${ }^{16,26,32}$ In the retrospective study of ICU medications by Hertle et al., ${ }^{23}$ it is likely the " $\mathrm{S}$ " enantiomer of ketamine, which is available in Europe, was used in many centers, as opposed to the racemic ketamine, which is available in the US. This may be relevant because of differences in potency and pharmacokinetics between these two types of ketamine ${ }^{14,36}$ Another design consideration is whether the periods that patients were on sedation regimens other than ketamine is truly a control group. In the retrospective data from Hertle et al., ${ }^{23}$ neither propofol nor midazolam had a significant effect on overall SD occurrence; however, midazolam slightly increased the odds of clusters of SD, and propofol slightly decreased these odds. ${ }^{23}$ Certainly, there may be clinically relevant effects of other such medications that could potentially influence any comparative study. Since the predominant other medication was propofol, which had a nonsignificant trend toward decreased SD in the retrospective review, ${ }^{23}$ it is possible that any potential therapeutic effect in our study could have led to an underestimation of the therapeutic effect of ketamine. Other interactions, such as with dexmedetomidine, are also possible; however, given the relatively short therapeutic halflives of all the sedation medications used, such contamination is unlikely to have had a minimal overall effect on the results.

In addition, our data seem to add further support to the argument that ketamine does not cause increased ICP, even in patients with severe brain injury. We found no overall effect of ketamine dose on ICP and on individual patient analysis; in fact, we found more patients with trends toward decreased ICP with higher doses of ketamine than those with a positive association.

Regarding timing of treatment, it is also unclear whether detection of SD is necessary to treat TBI and SAH patients, or whether SD-directed therapy should be universally given to SD-prone patients. On one hand, treating all patients may expose some patients who are lower risk to the side effects of the therapy; on the other hand, there are limitations in immediate bedside detection of SD, so that even in patients with continuous ECoG strip recording, 
there is a potential risk that SD could be occurring in a region distant from the strip.

Our study has limitations that prevent immediate adoption into clinical practice. We did not perform analysis per patient due to the multiple crossover design, and so no outcome data could be evaluated. This multiple crossover design allowed us to perform a pilot proof-of-concept trial as a stepping stone to larger trials. We did not perform a pharmacokinetic analysis, and so it is possible that the administered dose could have a variable relationship to the true plasma concentration depending on factors such as length of administration and other medication interactions. This will be an important topic in future trials. The study group was somewhat heterogeneous, with 2 TBI patients. Although pathophysiology can be very different in these two groups, SD is documented in both, and thus we considered it reasonable to group them for pilot testing. There is some potential imbalance in groups also because in the times when no sedation was required, our ketamine group was given subtherapeutic ketamine while the standard group received no medication. Since no therapeutic effect was noted at doses lower than $0.55 \mathrm{mg} / \mathrm{kg} / \mathrm{hr}$, these very low dose times probably did not significantly affect our primary results. Finally, there are inherent sampling limitations with currently used SD monitoring techniques. The electrode strip only monitors a small region of the brain, and though the strip is positioned in what is thought to be the most susceptible region to ischemia, it is possible that it is not representative of SD occurring in more distant, vulnerable tissue. Based on animal data, it has been hypothesized that the SD demonstrated on the electrode is representative of events occurring remotely, ${ }^{10,32}$ but this has not yet been confirmed.

Based on previous studies, we expected a dose dependency to the treatment, but since a minimum effective dose has not been clearly defined, we chose to perform this pilot trial pragmatically, using only clinically required sedation. This led to many hours of treatment at very low, subanesthetic doses. It remains possible that there is a beneficial effect on the SD morphology at these lower doses; ${ }^{28}$ our relatively small numbers did not confirm this hypothesis. This is certainly a topic for future investigation since in future trials, dosing must be well below the threshold for respiratory depression in awake patients. A dose of 1 $\mathrm{mg} / \mathrm{kg}$ is widely accepted as safe for procedural sedation, with very rare reports of cardiorespiratory side effects, ${ }^{35}$ and thus it may be a reasonable starting point for such future study. Ketamine is widely and safely used, even in an outpatient environment, but potential side effects and toxicities, including sensorial side effects and respiratory depression, can occur, particularly at higher doses; ${ }^{8}$ therefore, selective use in high-risk patients might avert potential concerns regarding such over-sedation and associated pneumonia and deep venous thrombosis in the ICU.

In future studies, there are many refinements that will be required to prove efficacy of SD suppression as a means to improving clinical outcome. First, selection of patients is key and with current monitoring systems, it may now be possible to detect SD at the bedside ${ }^{19}$ and only initiate treatment when SD has been documented. This will overcome the concern of treating patients who would not be expected to benefit from the treatment. Second, less invasive methods of monitoring SD are actively and rapidly being explored. Traditional scalp EEG may offer some hint at the cortical process ${ }^{13,21}$ but likely is not adequately spatially resolved to detect SD. Noninvasive methods are therefore a significant focus of future study to allow enrollment and treatment of patients not requiring craniotomy or burr hole.

\section{Conclusions}

Ketamine effectively inhibits SD over a wide range of doses commonly used for sedation, even in nonintubated patients. These data also provide the first prospective evidence that the occurrence of SD can be influenced by clinical intervention and does not simply represent an unavoidable epiphenomenon after injury. These data provide the basis for future studies assessing clinical improvement with SD-directed therapy.

\section{Acknowledgments}

Special thanks to Howard Yonas, MD, for support from the neurosurgery department and the ICU nurses and research coordinators who made this study possible, particularly Kim Olin, Kyna Seale, Amal Alchbli, and Brittany Burlbaw.

Support was provided by the National Center for Advancing Translational Sciences pilot grant no. 1UL1TR001449-01 to the Clinical Translational Science Center (to A.P.C.) and NIH grants nos. NS106901 and GM109089 (to C.W.S.).

\section{References}

1. Agresti A, Kateri M: Categorical data analysis, in Lovric M (ed): International Encyclopedia of Statistical Science. Berlin: Springer, 2011

2. Aiba I, Shuttleworth CW: Sustained NMDA receptor activation by spreading depolarizations can initiate excitotoxic injury in metabolically compromised neurons. J Physiol 590:5877-5893, 2012

3. Armitage P: Tests for linear trends in proportions and frequencies. Biometrics 11:375-386, 1955

4. Bosche B, Graf R, Ernestus RI, Dohmen C, Reithmeier T, Brinker G, et al: Recurrent spreading depolarizations after subarachnoid hemorrhage decreases oxygen availability in human cerebral cortex. Ann Neurol 67:607-617, 2010

5. Carlson AP, Carter RE, Shuttleworth CW: Vascular, electrophysiological, and metabolic consequences of cortical spreading depression in a mouse model of simulated neurosurgical conditions. Neurol Res 34:223-231, 2012

6. Cochran WG: Some methods for strengthening the common $\chi^{2}$ tests. Biometrics 10:417-451, 1954

7. Cohen L, Athaide V, Wickham ME, Doyle-Waters MM, Rose NG, Hohl CM: The effect of ketamine on intracranial and cerebral perfusion pressure and health outcomes: a systematic review. Ann Emerg Med 65:43-51, 51.e1-51.e2, 2015

8. De Pinto M, Jelacic J, Edwards WT: Very-low-dose ketamine for the management of pain and sedation in the ICU. J Opioid Manag 4:54-56, 2008

9. Dreier JP: The role of spreading depression, spreading depolarization and spreading ischemia in neurological disease. Nat Med 17:439-447, 2011

10. Dreier JP, Fabricius M, Ayata C, Sakowitz OW, Shuttleworth $\mathrm{CW}$, Dohmen C, et al: Recording, analysis, and interpretation of spreading depolarizations in neurointensive care: review 
and recommendations of the COSBID research group. $\mathbf{J}$ Cereb Blood Flow Metab 37:1595-1625, 2017

11. Dreier JP, Major S, Manning A, Woitzik J, Drenckhahn C, Steinbrink J, et al: Cortical spreading ischaemia is a novel process involved in ischaemic damage in patients with aneurysmal subarachnoid haemorrhage. Brain 132:1866-1881, 2009

12. Dreier JP, Woitzik J, Fabricius M, Bhatia R, Major S, Drenckhahn C, et al: Delayed ischaemic neurological deficits after subarachnoid haemorrhage are associated with clusters of spreading depolarizations. Brain 129:3224-3237, 2006

13. Drenckhahn C, Winkler MK, Major S, Scheel M, Kang EJ, Pinczolits A, et al: Correlates of spreading depolarization in human scalp electroencephalography. Brain 135:853-868, 2012

14. Duque JC, Oleskovicz N, Guirro ECBP, Valadão CAA, Soares VE: Relative potency of ketamine and S(+)-ketamine in dogs. J Vet Pharmacol Ther 31:344-348, 2008

15. Feuerstein D, Manning A, Hashemi P, Bhatia R, Fabricius $\mathrm{M}$, Tolias C, et al: Dynamic metabolic response to multiple spreading depolarizations in patients with acute brain injury: an online microdialysis study. J Cereb Blood Flow Metab 30: $1343-1355,2010$

16. Gorelova NA, Koroleva VI, Amemori T, Pavlík V, Burĕs J: Ketamine blockade of cortical spreading depression in rats. Electroencephalogr Clin Neurophysiol 66:440-447, 1987

17. Hartings JA, Bullock MR, Okonkwo DO, Murray LS, Murray GD, Fabricius M, et al: Spreading depolarisations and outcome after traumatic brain injury: a prospective observational study. Lancet Neurol 10:1058-1064, 2011

18. Hartings JA, Li C, Hinzman JM, Shuttleworth CW, Ernst GL, Dreier JP, et al: Direct current electrocorticography for clinical neuromonitoring of spreading depolarizations. J Cereb Blood Flow Metab 37:1857-1870, 2017

19. Hartings JA, Shuttleworth CW, Kirov SA, Ayata C, Hinzman JM, Foreman B, et al: The continuum of spreading depolarizations in acute cortical lesion development: examining Leão's legacy. J Cereb Blood Flow Metab 37:1571-1594, 2017

20. Hartings JA, Watanabe T, Bullock MR, Okonkwo DO, Fabricius M, Woitzik J, et al: Spreading depolarizations have prolonged direct current shifts and are associated with poor outcome in brain trauma. Brain 134:1529-1540, 2011

21. Hartings JA, Wilson JA, Hinzman JM, Pollandt S, Dreier JP, DiNapoli V, et al: Spreading depression in continuous electroencephalography of brain trauma. Ann Neurol 76:681694, 2014

22. Hernándéz-Cáceres J, Macias-González R, Brozek G, Bures $\mathrm{J}$ : Systemic ketamine blocks cortical spreading depression but does not delay the onset of terminal anoxic depolarization in rats. Brain Res 437:360-364, 1987

23. Hertle DN, Dreier JP, Woitzik J, Hartings JA, Bullock R, Okonkwo DO, et al: Effect of analgesics and sedatives on the occurrence of spreading depolarizations accompanying acute brain injury. Brain 135:2390-2398, 2012

24. Hinzman JM, Andaluz N, Shutter LA, Okonkwo DO, Pahl $\mathrm{C}$, Strong AJ, et al: Inverse neurovascular coupling to cortical spreading depolarizations in severe brain trauma. Brain 137:2960-2972, 2014

25. Leao AAP: Spreading depression of activity in the cerebral cortex. J Neurophysiol 7:359-390, 1944

26. Marrannes R, Willems R, De Prins E, Wauquier A: Evidence for a role of the N-methyl-D-aspartate (NMDA) receptor in cortical spreading depression in the rat. Brain Res 457:226240,1988
27. Nakamura H, Strong AJ, Dohmen C, Sakowitz OW, Vollmar $\mathrm{S}$, Sué M, et al: Spreading depolarizations cycle around and enlarge focal ischaemic brain lesions. Brain 133:1994-2006, 2010

28. Reinhart KM, Shuttleworth CW: Ketamine reduces deleterious consequences of spreading depolarizations. Exp Neurol 305:121-128, 2018

29. Riker RR, Picard JT, Fraser GL: Prospective evaluation of the Sedation-Agitation Scale for adult critically ill patients. Crit Care Med 27:1325-1329, 1999

30. Roberts DJ, Hall RI, Kramer AH, Robertson HL, Gallagher $\mathrm{CN}$, Zygun DA: Sedation for critically ill adults with severe traumatic brain injury: a systematic review of randomized controlled trials. Crit Care Med 39:2743-2751, 2011

31. Sakowitz OW, Kiening KL, Krajewski KL, Sarrafzadeh AS, Fabricius M, Strong AJ, et al: Preliminary evidence that ketamine inhibits spreading depolarizations in acute human brain injury. Stroke 40:e519-e522, 2009

32. Sánchez-Porras R, Santos E, Schöll M, Stock C, Zheng Z, Schiebel P, et al: The effect of ketamine on optical and electrical characteristics of spreading depolarizations in gyrencephalic swine cortex. Neuropharmacology 84:52-61, 2014

33. Schiefecker AJ, Beer R, Pfausler B, Lackner P, Broessner G, Unterberger I, et al: Clusters of cortical spreading depolarizations in a patient with intracerebral hemorrhage: a multimodal neuromonitoring study. Neurocrit Care 22:293-298, 2015

34. Somjen GG: Mechanisms of spreading depression and hypoxic spreading depression-like depolarization. Physiol Rev 81:1065-1096, 2001

35. Strayer RJ, Nelson LS: Adverse events associated with ketamine for procedural sedation in adults. Am J Emerg Med 26:985-1028, 2009 (Erratum in Am J Emerg Med 27:512, 2009)

36. Vollenweider FX, Leenders KL, Øye I, Hell D, Angst J: Differential psychopathology and patterns of cerebral glucose utilisation produced by (S)- and (R)-ketamine in healthy volunteers using positron emission tomography (PET). Eur Neuropsychopharmacol 7:25-38, 1997

37. von Bornstädt D, Houben T, Seidel JL, Zheng Y, Dilekoz E, Qin T, et al: Supply-demand mismatch transients in susceptible peri-infarct hot zones explain the origins of spreading injury depolarizations. Neuron 85:1117-1131, 2015

\section{Disclosures}

The authors report no conflict of interest concerning the materials or methods used in this study or the findings specified in this paper.

\section{Author Contributions}

Conception and design: Carlson, Alunday, Shuttleworth. Acquisition of data: Carlson, Abbas. Analysis and interpretation of data: Carlson, Abbas, Shuttleworth. Drafting the article: Carlson. Critically revising the article: all authors. Reviewed submitted version of manuscript: all authors. Approved the final version of the manuscript on behalf of all authors: Carlson. Statistical analysis: Carlson, Qeadan. Study supervision: Shuttleworth.

\section{Correspondence}

Andrew P. Carlson: University of New Mexico, Albuquerque, NM. andrewcarlson@salud.unm.edu. 